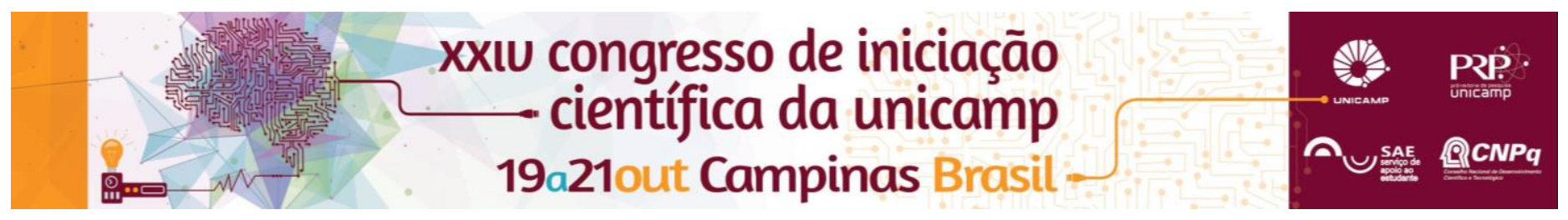

\title{
Effects of oral administration of linoleic acid (LA) on tissue repair in mice undergoing experimental diabetes.
}

\section{Mariah B. P. dos Anjos*, Carolina M. C. Kühl, Thamiris Candreva, Beatriz Burger, Hosana G. Rodrigues.}

\section{Abstract \\ The aim about this project is identify and characterize the effects of linoleic acid}

\section{Key words:}

Inflammation, wound healing, fatty acid..

\section{Introduction}

The skin is the biggest barrier against external agressions to the body so, any, damage to it must be quickly repaired. During this process, immune cells are activated and produce molecules called cytokines, wich may be modulated by some nutrientes, such as fatty acids. Previously, we demonstrated that linoleic acid (LA) modulated the inflammatory phase of wound healing in non-diabetic rats, increasing the initial production of proinflammatory cytokines. Uncontrolled hyperglycimia is a condition presente in diabetes and it is related to cronification of wounds, and can result in lower limb amputation, due to wound infection Thus, it is crucial to investigate molecules that can improve the tissue repair in diabetic condition.

1. Methodology

\section{Results and Discussion}

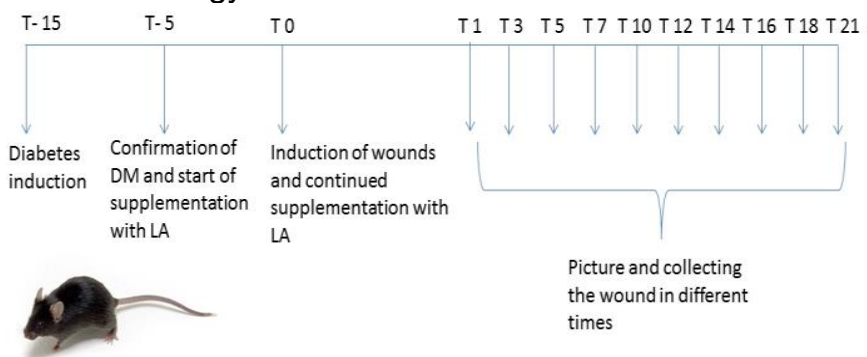

Cytokines were determined by ELISA.

Statistical analysis were performed using Student $T$ test.

Results were considered significant when $p<0,05$.

\section{Results and Discussion}

Glycemia was be increase on group submite to induce type-1 diabetes melitus.

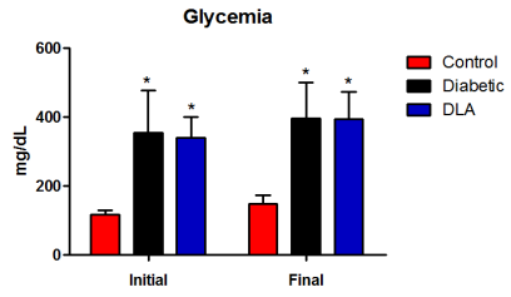

Figure 1. Glycemia was be elevated on groups submite to induce type-1 diabetes melitus. Glycemia, initial and final, animals control (C), diabetic (D) and treated diabetic (DLA). Values presented as mean \pm standart deviation of de average. $\left(^{*}\right)$ different compared to control.
The treatment with linoleic acid normalized closing wounds.
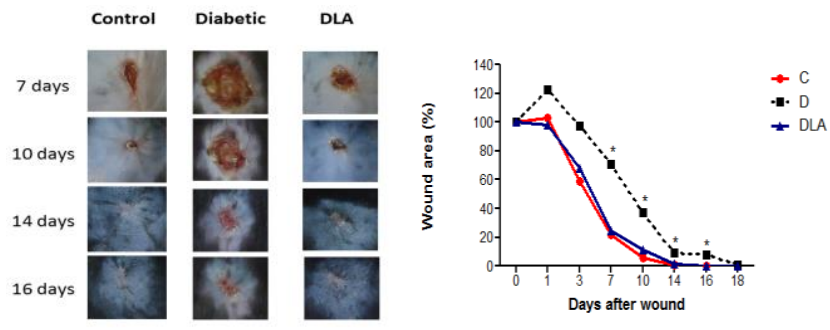

Figure 2. The wound area on time line. Wound closure in control animals (C), diabetic (D), treated diabetic (DLA). Values expressed as mean \pm standard deviation of the mean. $\left(^{*}\right)$ different compared to control.

The treatment with linoleic acid increase IL-1 $\beta$, VEGF and reduce TNF- $\alpha$.

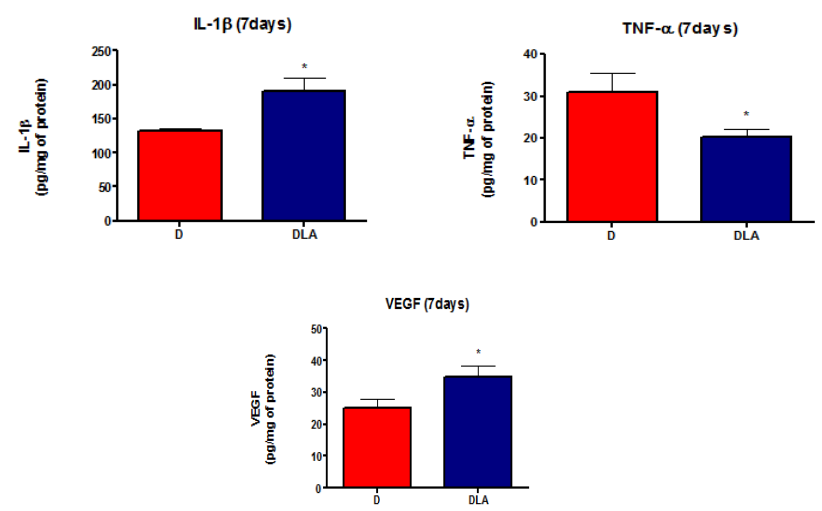

Figure 3. Cytokines production. Wound tissue of 7 days from diabetic (D) and treated diabetic (DLA) groups. Values expressed as mean \pm standard deviation of the mean. $\left.{ }^{*}\right)$ different compared to control.

\section{Conclusions}

As preliminary conclusions, animals subjected to oral supplementation of pure linoleic acid showed a better tissue repair compared to the diabetic group. These results may be associated with the modulation of inflammatory phase of healing process.

\section{Acknowledgement}

\section{FAPESP, CNPq, CAPES e FAEPEX / UNICAMP} inflammatory phase of wound healing. Journal of Investigative Dermatology, v. 132, p. 208 $215,2012$. 